\title{
The Discriminant Analysis: an Exploratory Study Concerning the Degree of Financial Autonomy of Companies in the Context of the Romanian Business Environment
}

\author{
Marilena Mironiuc, University of Iaşi, Romania \\ Mihaela-Alina Robu, University of Iaşi, Romania \\ Ioan-Bogdan Robu, University of Iaşi, Romania
}

\begin{abstract}
This study aims at analyzing the evolution of financial autonomy on a sample of 80 companies quoted in the Bucharest Stock Exchange, between 2006-2008. Classically, financial autonomy is measured using the global and day-to-day rates of financial autonomy. However, this study has tested the dependency between the global rate of financial autonomy (Own Capital/ Total debts) and a series of economic and financial indicators, with the purpose of obtaining both a score function that would help making a classification of the companies subject to our analysis, in performance groups (companies with a high financial autonomy, companies with a medium financial autonomy, companies with a low financial autonomy, and companies with no financial autonomy), and quantifying the influence of the relative variations of these economic and financial indicators on the relative variation of financial autonomy. In order to calculate the results, the statistic instrument SPSS 15.0 was used, and the work method was the discriminant analysis and the regression and multiple correlation analysis.
\end{abstract}

\section{Keywords}

Cluster analysis, financial autonomy, internal financing, crisis, discriminant analysis.

JEL Code: G32, M41, C51, C53, G17

\section{Introduction}

The globalization phenomenon forces the countries of the world to live under the conditions of the recent international economic crisis. The malfunctionalities of the financial market, the collapse of crediting caused by a significant increase in the cost of debt and by more difficult access conditions to credits, the uncertainty related to regulations and the fiscal pressures in crisis situations, the worsening of the depression, all these are threats that endanger companies sustainability, which negatively influence value creation for the shareholders, and which determine financial autonomy to acquire higher valences for companies. In this period of crisis, the guilty for excessive debts from previous years are searched, among the debtors who have resorted to loans without ensuring the fact that they would be able to pay back their credits, and among the credit institutions that have encouraged their clients, thus contributing to the creation of a climate of "ignored risks" or risk transfer mainly on the debtors. The analysts tend to bias the balance towards the creditors, who have infringed the principles of business ethics out of the desire to increase their profits in an opportunistic manner. The depression determines an "economic Darwinism", that is, the position of certain companies is consolidated based on the bankruptcy of others. In this context, solutions are searched and suggested for reanimating the capital market, for activating the inter-banking 
market, and for compensating the losses recorded on the financial market ${ }^{1}$. Therefore, the promotion of strategies that generate liquidity, through the design and implementation of fiscal measures that stimulate work, savings, and investments, the reduction of the real interest rate, and crediting upturn are essential for ensuring business continuity ${ }^{2}$.

\section{Conceptual Approaches on Financial Autonomy}

At the origin of the selection of a company's financing sources there always is a required amount for financing, which may cause financial imbalances and tensions within the firm. It is important for the internal resources to have a relevant weight in the financial structure of any company, which means a high degree of financial autonomy. Financial autonomy is a premise for access to credits, which proves that the company is not subject to the risk of insolvency as a result of a too high dependency on creditors who, under these circumstances, will not intervene in the company's decision-making process. Therefore, internal resources represent a guarantee of the company's solvency. If this guarantee is insufficient, the sponsors will require additional guarantees in order to allow access to their capital.

The degree of financial autonomy is directly conditioned upon the size of the internal contributions of any company (internal financing), represented by resources such as: net profit or profit remained after paying the dividends; the amortization of locked up assets, and the amounts resulted from disinvestments (usage of the locked up assets that are out of function or of selling the surplus assets); other funds assimilated to the internal capital, as well as natural or financial contributions of the future owners. Each of the two modalities of building the company's capital presupposes costs and implies certain obligations for the sponsors.

Internal financing implies obtaining a significant profit, of which a part is reinvested for increasing the locked assets and for funding the exploitation cycle. The accumulation of capital by reserving undistributed profit creates a double advantage for the company: it strengthens the company's financial autonomy and its ability to make debts. Amortization is also used for internal financing, which is the expression of the depreciation of the fixed means, in which part of the company's social capital is locked and that has the role to preserve its productive potential, by renewing the locked up assets and covering the exploitation risks. In the conditions of a significant development of the company, internal financing is not enough, but it ensures:

- The fact that the company is in its turn interested in obtaining higher economical and financial results, mobilizing internal reserves and using them efficiently, which encourages the capital contributions of new shareholders ${ }^{3}$;

- Increasing the company's interest for self-development, independence, and financial autonomy;

- Building a safe method for covering the required amount to be financed, considering that in certain conjectural situations the company may encounter difficulties in obtaining capital from the financial market;

- Financing for risky investments and intact preservation of the company's ability to acquire debts.

\footnotetext{
${ }^{1}$ Naifar, N. (2008), La récente crise financière internationale cause t-elle la crise des marchés des swaps sur défaut de crédit ?, MPRA Paper No. 11909, p.1, http://mpra.ub.unimuenchen.de,

${ }^{2}$ Mironiuc, M. (2009), Risk Management in the New European Context: Methodological Approaches, Scientific Works. Horticulture Series, Year I.II. Vol. 52, "Ion Ionescu de la Brad" Publishing House, Iaşi, p. 263

${ }^{3}$ Vasile, I. (2005), Gestiunea financiară a întreprinderii, Meteor Press Publishing House, Bucharest, p. 204
} 
According to certain opinions, internal financing tends to diminish capital mobility at a high extent ${ }^{4}$. Although internal financing is the expression of a healthy financial policy, exaggerations in this direction are not recommended, since the company needs to preserve its relationship with the financial market. Certain companies that integrally cover their costs for economic development from internal financing are tempted to neglect the cost of the own capital, considering it as free of charge. But the economic and financial reality proves that, irrespective of its provenience, capital has a cost and sometimes the cost of the own capital is higher than the cost of the borrowed capital. Any policy for internal financing needs to be analyzed according to the profitability of the reinvested profit. If the profitability of the new investment projects covered by internal financing is equal to the profitability rate requested by the shareholders who have invested their capital in the company, then the internal financing policy is neutral. Only when the profitability of the investments covered by internal financing is higher than the rate of profitability that pays back to the shareholders, the internal financing policy has a positive effect on the company, expressed in an increase of its value. As a consequence, internal financing contributes to the increase of the company's capital, but does not allow any profit increase unless the profitability rate of the investment projects surpasses the profitability requested by the shareholders ${ }^{5}$.

The capital contribution adds to the financial autonomy of the company, but also implies a diminution of power and a division of the company's net result between the capital "contributors". The decision to pay the shareholders through dividends influences the company's policies related to capital accumulation, internal financing, and investment. The dividend policy has, at the first sight, opposed effects on the company and its shareholders. On the one hand, distributing dividends deprives the firm from a fraction of its internal financing, which means a loss of liquidity, for which advantageous placements could have been found. On the other hand, the dividend policy ensures that the shareholders who have made financial placements are paid back. Therefore, there can be noticed an opposition between the company's interests, as an economic entity and as a decision center oriented towards accumulating capital and power, and the shareholders, as third parties whose interest is represented by a remuneration for their risk capital placed within the company. This opposition tends to diminish as capital accumulation transforms, on the long term, in additional value for the shareholders. Internal financing is an indicator with a rich informational value for the company, its creditors, and its investors. It is carefully monitored by the company, for which it represents the safest financing resource, ensuring its financial independence. Creditors analyze internal financing because it is a clue regarding the company's access to credits and its ability to pay them back. Internal financing convinces potential investors that the company is able to efficiently use and manage the given capital and that they are guaranteed an attractive payback for the risks taken through investments.

\section{Research Methodology}

Considering the determinant factors of financial autonomy, in this article we aim at testing two working hypotheses:

a) The existence of interdependencies between a series of rates (which we will name, from now on, independent variables), and the rate of global financial autonomy, which will be expressed in the description of a score function, which can be used as an instrument for classifying the companies from the analyzed sample. The score function will have the form: $\mathbf{Y}=\mathbf{a}_{1} \times \mathbf{X}_{1}+\mathbf{a}_{\mathbf{2}} \times \mathbf{X}_{\mathbf{2}}+\ldots+\mathbf{a}_{\mathbf{8}} \times \mathbf{X}_{\mathbf{8}}$, where $\mathbf{Y}$ is the dependent variable of the suggested model, taking the following values: $\mathbf{1}$ - High autonomy, $\mathbf{2}$ - Medium autonomy, $\mathbf{3}$ - Low

\footnotetext{
${ }^{4}$ Conso, P., Hemici, F. (2005), Gestion financière de l'entreprise, $11^{\text {th }}$ Edition, Dunod, Paris, p. 207

${ }_{5}^{5}$ Mironiuc, M. (2009), Fundamentele ştiinifice ale gestiunii financiar-contabile, The Publishing House of "Alexandru Ioan Cuza" University, Iaşi, p. 63
} 
autonomy, 4 - No financial autonomy. In order to include the companies in our sample in one of these four classes suggested, the debt degree was taken into account (Total debts/Own capital). Therefore, four intervals were formed: for $(\mathrm{Dtot} / \mathrm{OC}) \in[0 ; 0,7]$ we will associate a high degree of autonomy (1), for $(\operatorname{Dtot} / \mathrm{OC}) \in(0,7 ; 1]$ we will associate a medium degree of autonomy (2), for (Dtot/OC) $\in(1 ; 2]$ we will associate a low degree of autonomy (3), and for $($ Dtot $/ \mathrm{OC}) \in(2 ;+\infty) \mathrm{U}(-\infty ; 0)$ we will associate an inexistence of financial autonomy (4). The independent variables $\mathbf{X}_{\mathbf{i}}$ (with $\mathbf{i}=1: 8$ ) represent a series of rates which we have analyzed in this model: $\mathbf{X}_{\mathbf{1}}=$ The rate of total debt (Dtot/Ptot), $\mathbf{X}_{\mathbf{2}}=$ The rate of immediate liquidity $(\mathrm{AT} / \mathrm{Dc}), \mathbf{X}_{\mathbf{3}}=$ The rate of general solvency (Atot/Dtot), $\mathbf{X}_{\mathbf{4}}=$ The rate of general liquidity $(\mathrm{Ac} / \mathrm{Dc}), \mathbf{X}_{\mathbf{5}}=$ The rate of financial profitability (Rnet/OC), $\mathbf{X}_{\mathbf{6}}=$ The rate of commercial profitability (Rgross/CA), $\mathbf{X}_{7}=$ The rate of internal financing $(\mathrm{OC} / \mathrm{Ptot}), \mathbf{X}_{\mathbf{8}}=$ The degree of debt (Dtot/OC). The coefficients $\mathbf{a}_{1 \ldots 8}$ are the unknown factors of the suggested mathematical model, which will be calculated by solving the system of 80 equations (the size of the suggested sample of companies quoted in the Bucharest Stock Exchange-BSE) with 8 unknown factors (coefficients associated to each rate). The information collected and processed is from the period 2006-2008.

b) Based on the collected information, we aim to test the existence of connections between the relative variations of the independent variables in the model above and the relative variation of financial autonomy, variations that we will name elasticities. Two functions will be obtained (for the periods 2008-2007 and 2007-2006), under the following form ${ }^{6}$ :

$\mathbf{E A T F}=\mathbf{b}_{1} \times \mathbf{E L I}+\mathbf{b}_{2} \times \mathbf{E S G}+\mathbf{b}_{3} \times \mathbf{E L G}+\mathbf{b}_{4} \times \mathbf{E R F}+\mathbf{b}_{5} \times \mathbf{E R C}+\mathbf{b}_{6} \times \mathbf{E A F}+$ Const, where: $\mathbf{b}_{1 \ldots 6}=$ the coefficients of the model (unknown factors), Const - constant,

EATF - the elasticity of financial autonomy $\left[\left(\Delta \mathrm{OC} / \mathrm{OC}_{0}\right) /\left(\Delta \mathrm{Dtot} / \mathrm{Dtot}_{0}\right)\right]$,

ELI - the elasticity of immediate liquidity $\left[\left(\Delta \mathrm{AT} / \mathrm{AT}_{0}\right) /\left(\Delta \mathrm{Dc} / \mathrm{Dc}_{0}\right)\right]$,

ESG - the elasticity of general solvency $\left[\left(\Delta \mathrm{Atot}^{\mathrm{A}} / \mathrm{Atot}_{0}\right) /\left(\Delta \mathrm{Dtot} / \mathrm{Dtot}_{0}\right)\right]$,

ELG - the elasticity of general liquidity $\left[\left(\Delta \mathrm{Ac} / \mathrm{Ac}_{0}\right) /\left(\Delta \mathrm{Dc} / \mathrm{Dc}_{0}\right)\right]$,

ERF - the elasticity of financial profitability $\left[\left(\Delta\right.\right.$ Rnet $\left.\left.^{\prime} \mathrm{Rnet}_{0}\right) /\left(\Delta \mathrm{OC} / \mathrm{OCR}_{0}\right)\right]$,

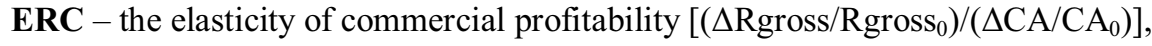

EAF - the elasticity of internal financing $\left[\left(\Delta \mathrm{OC} / \mathrm{OC}_{0}\right) /\left(\Delta \mathrm{Ptot} / \mathrm{Ptot}_{0}\right)\right]$.

Starting from the sample of the 80 Romanian companies quoted in the Bucharest Stock Exchange, discriminant function coefficients have been obtained for the years 2008, 2007, and 2006, using the direct method $^{7}$ (all variables were simultaneously taken into account). Using the statistic program SPSS15.0, a prognosis was also made concerning the inclusion of a company in one of the categories mentioned above, even if the respective company does not belong to the analyzed sample.

\section{Discussions on the Results}

After processing the database using SPSS 15.0, results for valid interpretations have been obtained, which will be later used in making decisions. The most important results are those that lead to calculating the coefficients of discriminant functions. Therefore, the standardized coefficients with higher values determine the importance and degree of contribution of the associated variable to the discriminant ability of the function. Table no. 1. points out the impact of each independent variable on the three suggested mathematical models, the influence power being given by the module value of the coefficients, while the meaning is given by the sign of each coefficient. According to the obtained data, for the function corresponding to 2006 , there can be noticed a significantly positive influence of The rate of

\footnotetext{
${ }^{6}$ Jaba, E., Jemna, D., Viorică, D., Balan, C. (2007), Discriminant analysis in the study of romanian regional economic development, The scientific annals of "Alexandru Ioan Cuza" University, Iaşi, tome LIV, Ştiințe Economice, Iaşi, p. 148

${ }^{7}$ Jaba, E., Robu, I-B. (2009), Utilizarea analizei discriminant pentru obținerea probelor de audit, Revista Audit Financiar, no. 11, Bucharest, p. 24
} 
global internal financing (OC/Ptot) - having a coefficient of 0.47 (maximum values of the ratio will determine the inclusion of the company within a group with high autonomy), but, negatively, a significant influence is shown by The rate of global debt (Dtot/Ptot), with a coefficient of -0.47 (maximum values of the ratio will indicate a low financial autonomy). For the year 2007, The rate of financial profitability (Rnet/OC) and The degree of debt (Dtot/OC) largely determine the classification of the companies in the three established categories (the coefficient of 2.56, associated to maximum values of the Rnet/OC ratio, contributes to including the companies in categories with high financial autonomy, while the coefficient of 2.43 , associated to Dtot/OC, determines the inclusion in a group with low financial autonomy).

Table no. 1. Coefficients, the structure matrix, and global means

\begin{tabular}{|l|r|r|r|r|r|r|r|r|r|}
\hline \multirow{2}{*}{ Variables } & \multicolumn{3}{|c|}{ Coefficients } & \multicolumn{3}{c|}{ Structure matrix } & \multicolumn{3}{c|}{ Sample means } \\
\cline { 2 - 10 } & $\mathbf{2 0 0 6}$ & $\mathbf{2 0 0 7}$ & $\mathbf{2 0 0 8}$ & $\mathbf{2 0 0 6}$ & \multicolumn{1}{|c|}{$\mathbf{2 0 0 7}$} & $\mathbf{2 0 0 8}$ & $\mathbf{2 0 0 6}$ & $\mathbf{2 0 0 7}$ & $\mathbf{2 0 0 8}$ \\
\hline (Dtot/Ptot) & -0.47 & 0.65 & 2.24 & $\mathbf{- 0 . 9 7}$ & $\mathbf{0 . 8 9}$ & $\mathbf{0 . 9 4}$ & 0.46 & 0.47 & 0.50 \\
(AT/Dc) & 0.06 & -0.17 & 0.18 & $\mathbf{0 . 9 6}$ & $\mathbf{- 0 . 8 7}$ & $\mathbf{- 0 . 9 2}$ & 0.71 & 1.40 & 1.21 \\
(Atot/Dtot) & 0.05 & -0.14 & 0.02 & 0.38 & -0.41 & 0.25 & 7.50 & 10.46 & 14.90 \\
(Ac/Dc) & 0.09 & -0.10 & 0.06 & 0.30 & -0.37 & 0.25 & 2.28 & 3.34 & 3.24 \\
(Rnet/OC) & 0.04 & 2.56 & 0.26 & 0.29 & -0.25 & -0.17 & 0.12 & 0.59 & 0.19 \\
(Rgross/CA) & -0.01 & -0.09 & -0.09 & -0.20 & $\mathbf{- 0 . 4 4}$ & 0.31 & 0.10 & -0.09 & -0.28 \\
(OC/Ptot) & 0.47 & -0.19 & 3.14 & 0.17 & -0.14 & 0.24 & 0.54 & 0.52 & 0.49 \\
(Dtot/OC) & -0.16 & 2.43 & 0.37 & -0.07 & 0.17 & -0.03 & 2.73 & -1.17 & -0.61 \\
\hline
\end{tabular}

At the level of the fiscal year 2008, the highest influence is given by the Rate of global debt (Dtot/Ptot) equal to 2.24, as well as by the Rate of internal financing (OC/Ptot) equal to 3.14. Using canonic coefficients, it is possible to obtain the mathematical model of the score function. Based on the data provided by this table (the coefficients section), score functions will be built for every year: Score $_{2008}=2.24 \times($ Dtot/Ptot $)+0.18 \times($ AT/Dc $)+0.02 \times$ $($ Atot/Dtot $)+0.06 \times($ Ac/Dc $)+0.26 \times($ Rnet/OC $)-0.09 \times($ Rgross/CA $)+3.14 \times($ OC/Ptot $)$ $+0.37 \times(D t o t / O C)$. The Structure matrix section points out the significant correlations, as well as their meaning, from the established variables and the score function. There is a correlation between each independent variable and the discriminant function. These connections are presented in absolute value, and the values that tend towards $+/-1$ indicate strong correlations between the variable and the score function, which will significantly influence the score of each company. As can be noted, for 2006, the Dtot/Ptot ratio will determine the inclusion of the companies in categories with an inferior financial autonomy, while the $A T / D c$ ratio will determine the inclusion of the companies in categories with a high financial autonomy.

Table no. 2. Group Statistics presents, in detail for each fiscal year and for each independent variable analyzed, the average value for the group to which the company belongs. Analyzing these values, there can be noticed the existence of important differences both between the average levels per group and from one year to another. The table also points out the number of cases validated for each individual class. Therefore, for the fiscal year 2008, the number of quoted companies that belong to the class of High autonomy is $\mathbf{4 0}$, for those in the class with Medium autonomy is 6, the class with Low autonomy includes $\mathbf{1 7}$ companies, and the class with No financial autonomy, 17 entities. Comparing with the other years, 2007 and 2006 , there can be noticed a slight drop in the number of companies with high and medium autonomy and a significant increase in the number of companies with a low financial autonomy. In order to be able to classify, at need, companies that do not belong to the analyzed sample but that are characterized by the same economic, financial, time and space criteria, the statistic instrument also allows prediction functions. 
Table no. 2. Group statistics

\begin{tabular}{|c|c|c|c|c|c|c|}
\hline & \multicolumn{3}{|c|}{ Average High autonomy } & \multicolumn{3}{c|}{ Average Medium autonomy } \\
\hline Indicators & $\mathbf{2 0 0 6}$ & $\mathbf{2 0 0 7}$ & $\mathbf{2 0 0 8}$ & $\mathbf{2 0 0 6}$ & $\mathbf{2 0 0 7}$ & $\mathbf{2 0 0 8}$ \\
\hline (Dtot/Ptot) & 0.20 & 0.18 & 0.18 & 0.44 & 0.44 & 0.46 \\
\hline (AT/Dc) & 1.24 & 2.40 & 2.10 & 0.39 & 0.29 & 0.36 \\
\hline (Atot/Dtot) & 13.64 & 17.77 & 28.30 & 2.30 & 2.29 & 2.18 \\
\hline (Ac/Dc) & 3.35 & 5.07 & 5.20 & 1.63 & 1.99 & 1.54 \\
\hline (Rnet/OC) & 0.089 & 0.04 & 0.01 & 0.11 & -0.04 & 0.01 \\
\hline (Rgross/CA) & 0.15 & -0.02 & -0.32 & 0.11 & 0.02 & 0.06 \\
\hline (OC/Ptot) & 0.79 & 0.80 & 0.80 & 0.57 & 0.53 & 0.53 \\
\hline (Dtot/OC) & 0.29 & 0.25 & 0.27 & 0.77 & 0.83 & 0.87 \\
\hline Cases & $\mathbf{3 9}$ & $\mathbf{4 4}$ & $\mathbf{4 0}$ & $\mathbf{1 1}$ & $\mathbf{8}$ & $\mathbf{6}$ \\
\hline & $\mathbf{A v e r a g e ~ L o w ~ a u t o n o m y ~}$ & Average No autonomy \\
\hline Indicators & $\mathbf{2 0 0 6}$ & $\mathbf{2 0 0 7}$ & $\mathbf{2 0 0 8}$ & $\mathbf{2 0 0 6}$ & $\mathbf{2 0 0 7}$ & $\mathbf{2 0 0 8}$ \\
\hline (Dtot/Ptot) & 0.55 & 0.58 & 0.58 & 0.91 & 1.08 & 1.18 \\
\hline (AT/Dc) & 0.14 & 0.16 & 0.44 & 0.15 & 0.17 & 0.20 \\
\hline (Atot/Dtot) & 1.82 & 1.76 & 1.73 & 1.25 & 1.13 & 1.05 \\
\hline (Ac/Dc) & 0.97 & 1.20 & 1.67 & 1.18 & 0.93 & 0.82 \\
\hline (Rnet/OC) & 0.10 & 0.04 & -0.06 & 0.19 & 2.29 & 0.93 \\
\hline (Rgross/CA) & 0.03 & 0.01 & -0.40 & -0.07 & -0.31 & -0.19 \\
\hline (CPR/Ptot) & 0.44 & 0.43 & 0.42 & 0.10 & -0.06 & -0.21 \\
\hline (Dtot/OC) & 1.26 & 1.38 & 1.40 & 8.93 & -6.11 & -5.19 \\
\hline Cases & $\mathbf{9}$ & $\mathbf{8}$ & $\mathbf{1 7}$ & $\mathbf{2 1}$ & $\mathbf{2 0}$ & $\mathbf{1 7}$ \\
\hline
\end{tabular}

\section{(1rând liber, 11 p.)}

These discriminant functions can be written as linear equations, whose coefficients can be found in the columns of Table no. 3 .

Table no. 3. Coefficients of the classification functions

\begin{tabular}{|c|r|r|r|r|r|r|}
\hline \multirow{2}{*}{ Indicators } & \multicolumn{3}{|c|}{ High Autonomy } & \multicolumn{3}{c|}{ Medium Autonomy } \\
\cline { 2 - 8 } & $\mathbf{2 0 0 6}$ & \multicolumn{1}{c|}{$\mathbf{2 0 0 7}$} & \multicolumn{1}{c|}{$\mathbf{2 0 0 8}$} & \multicolumn{1}{c|}{$\mathbf{2 0 0 6}$} & \multicolumn{1}{c|}{$\mathbf{1 0 0 7}$} & \multicolumn{1}{c|}{$\mathbf{2 0 0 8}$} \\
\hline (Dtot/Ptot) & 194.86 & 104.26 & 1257.49 & 199.60 & 103.40 & 1247.89 \\
\hline (AT/Dc) & 0.41 & 0.16 & 9.64 & 0.38 & -0.14 & 9.47 \\
\hline (Atot/Dtot) & 0.06 & 0.03 & -0.16 & 0.05 & 0.01 & -0.17 \\
\hline (Ac/Dc) & -0.58 & 0.26 & -1.96 & -0.75 & 0.28 & -2.00 \\
\hline (Rnet/CPR) & 1.07 & -1.12 & 22.72 & 0.92 & -0.82 & 22.63 \\
\hline (Rgross/CA) & 1.78 & 4.76 & -8.43 & 1.95 & 5.01 & -8.24 \\
\hline (OC/Ptot) & 203.82 & 106.63 & 1263.03 & 206.26 & 104.45 & 1251.80 \\
\hline (Dtot/OC) & -0.23 & -0.40 & 2.35 & -0.24 & -0.30 & 2.36 \\
\hline (Constant) & -100.45 & -54.40 & -627.81 & -103.02 & -52.20 & -616.81 \\
\hline \multirow{2}{*}{ Indicators } & \multicolumn{2}{|c|}{ Low Autonomy } & & & No Autonomy \\
\cline { 2 - 8 } & $\mathbf{2 0 0 6}$ & $\mathbf{2 0 0 7}$ & $\mathbf{2 0 0 8}$ & $\mathbf{2 0 0 6}$ & $\mathbf{2 0 0 7}$ & $\mathbf{2 0 0 8}$ \\
\hline (Dtot/Ptot) & 198.08 & 107.29 & 1274.5 & 198.92 & 107.80 & 1239.87 \\
\hline (AT/Dc) & 0.46 & -0.09 & 9.78 & 0.30 & 0.02 & 9.45 \\
\hline (Atot/Dtot) & 0.06 & 0.01 & -0.17 & 0.05 & 0.01 & -0.16 \\
\hline (Ac/Dc) & -0.91 & 0.22 & -2.09 & -0.65 & 0.20 & -1.99 \\
\hline (Rnet/OC) & 0.79 & -0.14 & 23.16 & 0.88 & -0.01 & 22.32 \\
\hline (Rgross/CA) & 1.94 & 5.13 & -8.65 & 1.79 & 4.21 & -8.26 \\
\hline (CPR/Ptot) & 203.27 & 107.56 & 1277.71 & 199.52 & 105.39 & 1238.57 \\
\hline (Dtot/OC) & -0.23 & -0.08 & 2.43 & -0.21 & -0.07 & 2.21 \\
\hline (Constant) & -100.59 & -55.85 & -642.98 & -100.59 & -56.12 & -608.34 \\
\hline
\end{tabular}


Therefore, for 2008, the discriminant function for the class with High autonomy is of the type: HIGH AUTONOMY SCORE $=1257.49 \times($ Dtot/Ptot $)+9.64(\mathrm{AT} / \mathrm{Dc})-0.16 \mathrm{x}$ $($ Atot/Dtot $)-1.96 \times($ Ac/Dc $)+22.72 \times($ Rnet/OC $)-8.43 \times($ Rgross $/ C A)+1263.03 \times$ $(\mathrm{OC} /$ Ptot $)+2.35 \times$ (Dtot/OC) - 627.81. A similar method will be used for building the prognosis function for the other autonomy classes. After obtaining the 4 functions, in order to classify a company that does not belong to the analyzed sample into one of the 4 categories mentioned above, the score corresponding to each function will be computed, and its maximum value (compared to the other calculated scores) will indicate the inclusion of the company in one of these 4 classes. The same process will be used for the years 2007 and 2006. After testing the interdependence relationships between the variations of the rates analyzed in this model, for the period 2006-2008, we will look at the results given in the tables below.

Table no. 4 presents the average elasticity corresponding to each economic rate, as well as the dispersion of the values from the average. If for the fiscal years 2006-2007 the average elasticity of financial autonomy was 5.48 (for an increase of $1 \%$ of Ptot, there is an increase by $5.48 \%$ units of $O C$ ), for the following period it increased up to 14.58 (an increase of $1 \%$ of Ptot will determine an increase of the level of $O C$ of up to $14.58 \%$ ).

Table nr. 4. Descriptive Statistics

\begin{tabular}{|l|r|r|r|r|}
\hline & \multicolumn{2}{|c|}{ 2006-2007 } & \multicolumn{2}{|c|}{ 2008-2007 } \\
\cline { 2 - 5 } & Average & Std. Deviation & Average & Std. Deviation \\
\hline The elasticity of financial autonomy & 5.48 & 36.74 & 14.58 & 100.87 \\
The elasticity of immediate liquidity & 0.02 & 57.53 & -0.06 & 50.40 \\
The elasticity of general solvency & 0.19 & 5.19 & 10.96 & 86.78 \\
The elasticity of general liquidity & 2.06 & 12.65 & 0.61 & 4.84 \\
The elasticity of financial & 40.00 & 242.99 & -159.44 & 1570.26 \\
profitability & & & & \\
The elasticity of commercial & -608.17 & 5224.08 & -42.32 & 241.54 \\
profitability & 4.96 & 28.28 & -1.40 & 80.48 \\
The elasticity of internal financing & & & \\
\hline
\end{tabular}

Such significant variations can also be observed at the level of the elasticity of general solvency (a multiplication by 57.68), the elasticity of financial profitability (a significant decrease of $298.6 \%$, attaining a negative elasticity), as well as at the level of the elasticity of commercial profitability (a significant invigoration tendency).

Table no. 5. Correlations between elasticities

\begin{tabular}{|c|c|c|c|c|c|c|c|c|}
\hline & & EFA & EIL & $\overline{\text { EGS }}$ & $\overline{\text { EGL }}$ & $\overline{\text { EFP }}$ & ECP & $\overline{\text { EIF }}$ \\
\hline \multirow{7}{*}{$\begin{array}{c}\text { Pearson } \\
\text { Correlation } \\
2007-2008\end{array}$} & EFA & 1.000 & -0.094 & 0.973 & -0.589 & 0.013 & 0.042 & -0.155 \\
\hline & EIL & -0.094 & 1.000 & -0.095 & -0.325 & -0.002 & 0.025 & 0.006 \\
\hline & EGS & 0.973 & -0.095 & 1.000 & -0.600 & 0.011 & 0.025 & 0.004 \\
\hline & EGL & -0.589 & -0.325 & -0.600 & 1.000 & -0.022 & 0.079 & 0.023 \\
\hline & EFP & 0.013 & -0.002 & 0.011 & -0.022 & 1.000 & -0.079 & -0.002 \\
\hline & ECP & 0.042 & 0.025 & 0.025 & 0.079 & -0.079 & 1.000 & 0.005 \\
\hline & EIF & -0.155 & 0.006 & 0.004 & 0.023 & -0.002 & 0.005 & 1.000 \\
\hline \multirow{7}{*}{$\begin{array}{c}\text { Pearson } \\
\text { Correlation } \\
\text { 2006-2007 }\end{array}$} & EFA & 1.000 & -0.047 & 0.299 & -0.105 & -0.030 & 0.049 & 0.529 \\
\hline & EIL & -0.047 & 1.000 & 0.053 & 0.758 & 0.016 & 0.029 & -0.027 \\
\hline & EGS & 0.299 & 0.053 & 1.000 & 0.094 & -0.002 & 0.095 & 0.031 \\
\hline & EGL & -0.105 & 0.758 & 0.094 & 1.000 & 0.007 & 0.012 & -0.062 \\
\hline & EFP & -0.030 & 0.016 & -0.002 & 0.007 & 1.000 & -0.098 & -0.029 \\
\hline & ECP & 0.049 & 0.029 & 0.095 & 0.012 & -0.098 & 1.000 & -0.013 \\
\hline & EIF & 0.529 & -0.027 & 0.031 & -0.062 & -0.029 & -0.013 & 1.000 \\
\hline
\end{tabular}


As Table no. 5 shows, between 2007-2008, the elasticity of financial autonomy is positively influenced by the elasticity of general solvency (a positive modification of the general solvency will trigger an increase of the financial autonomy), while the elasticity of general liquidity will influence it in the opposite direction (a positive modification of the general liquidity will trigger a decrease in the financial autonomy). The synthesis of the influences of elasticities (the main variables in the model) on the elasticity of financial autonomy can be reflected in equations that transpose these connections, according to Table no. 6.

Table no. 6. Coefficients

\begin{tabular}{|l|r|r|}
\hline \multirow{2}{*}{$\begin{array}{c}\text { Model } \\
\text { Dependent variable: The elasticity of financial } \\
\text { autonomy }\end{array}$} & \multicolumn{2}{|c|}{ Un-standardized Coefficients } \\
\cline { 2 - 3 } & $\mathbf{2 0 0 6 - 2 0 0 7}$ & $\mathbf{2 0 0 7 - 2 0 0 8}$ \\
\hline (Constant) & 2.859 & 2.399 \\
The elasticity of immediate liquidity & 0.041 & -0.007 \\
The elasticity of general solvency & 2.060 & 1.127 \\
The elasticity of general liquidity & -0.436 & -0.124 \\
The elasticity of financial profitability & -0.002 & 0.000 \\
The elasticity of commercial profitability & 0.000 & 0.008 \\
The elasticity of internal financing & 0.666 & -0.200 \\
\hline
\end{tabular}

Therefore, for the periods 2006-2007 and 2007-2008, the regression equations have the form: $\mathrm{EFA}_{06-07}=0.041 \times \mathrm{EIL}+2.06 \times \mathrm{EGS}-0.436 \times \mathrm{EGL}-0.002 \times \mathrm{EFP}+0.666 \times \mathrm{EFC}+2.859$. $\mathrm{EFA}_{07-08}=-0.007 \times$ EIL $+1.127 \times$ EGS $-0.124 \times$ EGL $+0.008 \times E C P-0.200 \times E I F+2.399$.

\section{Conclusions}

Previous analyses allow us to notice that the companies characterized by the best degree of financial autonomy are those with the highest levels of the indicators for solvency, immediate liquidity, general liquidity, and profitability. The companies with no financial autonomy are oversaturated from the point of view of their debts, which has determined, in some cases, an erosion of the own capital by a carry-forward of the losses from the previous years (an effect of the absorption of the exploitation result by the financial expenses). Our study points out a reverse correlation between the degree of financial autonomy and the rate of financial profitability. As a paradox, the companies in the group with no financial autonomy are characterized by higher levels of the rates of financial profitability than the rates of the financial profitability of the companies included in the group with a high financial autonomy. This cannot be explained by the positive leverage effect determined by debt in case of companies with no financial autonomy, as it is a false profitability, determined for certain subjects by the reduced amount of their own capital (which mathematically intervenes in the denominator of the profitability ratio) or, for others, through a significant negative net result (loss) for a negative own capital (eroded by debt).

From the analysis of the elasticity of financial autonomy in relation with the elasticity of the economic and financial indicators included in the built score functions, there can be noticed a direct and intense interdependence between the company's financial autonomy and their solvency, which confirms the assertion that the internal resources represent a guarantee of the company's solvency. Also, the correlations between elasticities stress the diminution of the financial autonomy as an effect of the increase in the general liquidity. In order to explain this correlation, we take into account the fact that an increase in the rate of general liquidity may mean an increase, at a higher rate, of the floating assets in relation with the increase rate of the current liabilities. However, in fact, floating assets are not represented solely by investments in titles that can easily become liquid (treasury equivalents), but also by 
commercial stocks and receivables that absorb significant financial resources. In this case, an increase in the rate of general liquidity is a signal for increasing the temporary necessary amount to be funded and for the diminution of the financial autonomy.

\section{Bibliography}

1. Conso, P., Hemici, F. (2005), Gestion financière de l'entreprise, $11^{\mathrm{e}}$ édition, Dunod, Paris

2. Dallocchio, M., Salvi A. (2004), Finanza d'azienda, EGEA, Milano

3. Jaba, E., Robu, I-B. (2009), Utilizarea analizei discriminant pentru obținerea probelor de audit, Revista Audit Financiar, nr. 11, Bucureşti

4. Jaba, E., Jemna, D., Viorică, D., Balan, C. (2007), Discriminant analysis in the study of romanian regional economic development, Analele ştiințifice ale Universității „Alexandru Ioan Cuza” Iaşi, tomul LIV, Ştiințe Economice, Iaşi

5. Mironiuc, M. (2009), Analiză economico-financiară. Performanță-Poziție financiară-Risc, Editura Universității ,Alexandru Ioan Cuza”, Iaşi

6. Mironiuc, M. (2009), Fundamentele ştiințifice ale gestiunii financiar-contabile a întreprinderii, Editura Universității „Alexandru Ioan Cuza” Iaşi

7. Pavarani, E., ş.a. (2002), Analisi finanziaria. Valore, solvibilità, rapporti con i finanziatori, The McGraw-Hill Companies, Publishing Group Italia, Milano

8. Vintilă, G. (2005), Gestiunea financiară a întreprinderii, Ed. Didactică şi Pedagogică, Bucureşti

9. Vasile, I. (2005), Gestiunea financiară a întreprinderii, Editura Meteor Press, Bucureşti 